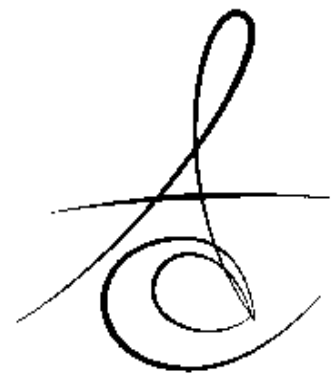

Makale Kodu/Article code: 1114

Makale Gönderilme tarihi: 04.03 .2013

Kabul Tarihi: 28.06.2013

\section{TAM SERAMİKLERİN DİŞHEKİMLİĞİNDEKİ YERİ}

PLACE OF FULL CERAMICS IN DENTISTRY

\author{
Dr. Cumhur KORKMAZ*
}

\section{ÖZET}

Teknolojinin gelişmesiyle birlikte günümüzde uygulanan tüm dental tedavilerde estetik, hastalar tarafından ön planda tutulmaktadır. Bu gelişmelerin paralelinde, protetik tedavi seçenekleri de daha estetik malzeme seçimine doğru kaymaktadır. Bu gereksinimler nedeniyle geliştirilen tam seramikler, diş hekimliğinde gün geçtikçe daha da yaygın olarak kullanılmaktadır. Tam seramikler konusu bilimsel araştırmalar içinde de önemli bir yer tutmaktadır. Ancak tam seramiklerin üstün estetik özelliklerinin yanında kırılganlıkları önemli bir dezavantaj oluşturur. Derlemede tam seramiklerin tarihçesi, güçlendirilme yöntemleri, avantajları, dezavantajları ve endikasyonları geniş literatür desteğiyle sunulmuştur.

Anahtar kelimeler: Estetik, Protetik restorasyon, Tam seramik

\section{GİRIŞ}

Yunanca "keramikos" sözcüğünden türemiş olan seramik, M.Ö.50'li yıllarda Çinliler tarafından kullanılmış, XVI. Yy'da Portekizli denizciler tarafından Avrupa'ya getirilmiştir. Seramik, protetik tedavide ilk olarak 1774 yılında Fransız eczacı Duchateau tarafından kullanılmıştır. İlk seramik diş materyali patentini, 1789 yılında, Fransız diş hekimi Chamont, Duchateau ile birlikte almıştır. ${ }^{1,2}$

Gelişen teknoloji ile beraber bireylerin estetik anlayışlarındaki değişiklikler, biyouyumluluk ve optik özellikler konusundaki beklentilerin artması, metal destekli porselen çalışmalarını da etkilemiş ve

\section{ABSTRACT}

Stress analysis techniques are being used in All of the dental treatments in current, together with technological progress, the aesthetic is also kept in mind by patients. In parallel with these developments, prosthetic treatment options is shifting to more aesthetic the choice of materials. All ceramics which developed by cause of the aesthetic requirements are used much more widely in dentistry. All seramics subject is also important for scientific researches. However, in addition to the exact aesthetics properties of all ceramics, vulnerabilities creates a significant disadvantage. In this review, the history of all ceramics, the strengthening of the methods, their advantages, disadvantages and indications are presented by the support of a wide literature.

Key words: Prosthodontic restoration, full ceramic, aesthetic.

kullanılan metal alt yapı materyali yerine yeni arayışların doğmasına neden olmuştur. ${ }^{3}$ Böylece estetik açıdan üstün, metal desteksiz porselen kullanımı gündeme gelmiştir. ${ }^{3,5}$

Protetik tedavide kullanılan seramiğin kırılgan olması restorasyonların metal alt yapı ile desteklenmesini zorunlu kılmıştır. Ancak kullanılan metal alt yapının, restorasyonun ışık geçirgenliğini engellemesi, metal-iyon renklenmelerinin görülmesi, zamanla korozyon oluşması ve bazı hastalarda alerjik reaksiyonlara neden olmasından dolayı kullanımında tereddütler oluşturmaktadır. ${ }^{4,6}$

Tek diş seramik kuronlar ilk defa 1808 yılında İtalyan asıllı diş hekimi Fonzi tarafından Paris'te yapılmış, fakat opasite ve kırılganlık nedeni ile başarılı

\footnotetext{
* Balıkesir Asker Hastanesi Diş Servisi
} 
olamamıştır.7 Seramikler 19. yy. sonlarında sabit restorasyonların yapımında kullanılmaya başlanmıştır. Seramik jaket kuron olarak bilinen ilk metal desteksiz kuron 1886 'da Land tarafından yapılmıştır. Bu restorasyon tipi yıllarca diş hekimliğinin sunduğu en estetik çözüm olarak kalmıştır. Malzemenin kırılganlığa olan yatkınlığı sebebiyle kullanım alanı ön tek diş restorasyonları ile sınırlı kalmıştır. ${ }^{17,9}$ İlk veneer kuron tanımı 1869 'da W.N Morrison tarafından yapılmıştır. 1889 'da C.H Land platin matriks üzerine seramik şekillendirmiş, 1900 yılından itibaren yüksek ısıda pişirilen seramikler ile veneer kuronların yapımı rutin olarak kullanıma girmiştir. 1907'de William H. Taggart diş hekimliğinde ilk olarak döküm örneği yapımında mumu kullanarak yeni bir döküm sistemi geliştirmiştir. ${ }^{10}$

1963 yılında Mc Lean ve Hughes alümina seramikleri geliştirerek günümüzdeki metal desteksiz sistemlerinin temelini oluşturmuşlardır. ${ }^{9} \quad$ Lityum disilikat, alüminyum oksit ve zirkonyum oksit gibi tam seramik alt yapı materyallerindeki gelişmeler tam seramik restorasyonların uygulama alanlarını genişletmiştir. ${ }^{7,8,11,13} 1980$ 'lerde dökülebilir cam seramik (Dicor ve Cerapearl) ve büzülme göstermeyen Cerestore alümina seramikler diş hekimliğinde kullanıma başlanmıştır. ${ }^{12}$ Bu sistemlerde kayıp mum tekniği kullanılarak anterior kuronlarda estetik sonuçlar elde edilmiştir. Ancak posterior restorasyonlarda görülen yüksek kırılma oranları ve yeni geliştirilen materyaller sebebiyle bu materyaller gözden düşmüştür. 1985 yılında piyasaya sürülen yüksek dirençli seramik sistemlerinden olan IPS Empress ve In-Ceram sistemleri benzersiz teknolojileri ve populariteleri ile geniş kullanım alanı bulmuşlardır. ${ }^{14}$

\section{Dental Seramikler Nasıl Güçlendirildi?}

Geleneksel seramikler ana madde olarak kil içerir ve cam matrix yapıya sahiptir. Bunun yanında alümina, feldspad, potas ve soda gibi metal oksitler de vardır. Tam seramik sistemler ya feldspatik seramiklerdir ya da tamamen farklı kompozisyonlara sahiptirler. ${ }^{33}$ Cam matriks ve kristal fazdan oluşan seramikler feldspatik seramikler olarak adlandırılır. Bu camlar düzensiz yapılarına ve gerçek kristalin yapılarda bulunan kaygan düzlemlerinin bulunmamasına bağı olarak kırılgan özellik taşımaktadırlar. Dental seramiklerin yüzeyinde oluşan bu kırılganlığa, yapısındaki çatlak ve yarıklar neden olmaktadır. Bu da seramiğin dayanıklıı̆ını etkiler. ${ }^{15,16,17}$ Yüzeydeki çatlak ve yarıkların varlığı, 1920 'de Griffith tarafından tanımlanmıştır ve Griffith
Kusurları olarak isimlendirilmiştir. ${ }^{22}$

Cam yapıdan oluşan seramik, gerilime maruz kaldığında, yüzeyindeki çatlaklar derinleşmeye başlar ve tüm gövde boyunca yayılır. Baskı stresleri ise seramik üzerinde yarıkları durdurma yönünde etki eder. Bu nedenle seramik yapı çekme gerilimlerine, baskı gerilimlerine oranla daha dirençsiz bir karakter sergiler. ${ }^{18-21}$

Yapılarındaki bu özellik nedeniyle seramikleri güçlendirmeye yönelik yöntemler geliştirilmiştir. Başlıca seramik güçlendirme metotlarını aşağıdaki şekilde sıralayabiliriz:

1. Metal alt yapıların kullanılması; seramik materyaller metal alaşımların dış oksit tabakasına bağlanmakta ve son derece dayanıklı restorasyonlar elde edilmektedir. ${ }^{22,23}$

2. Metal folyolara bağlanma; folyoyla güçlendirilmiş restorasyonlar, yapımlarının kolay olması bakımından döküm metal alt yapılara alternatif sağlamasının yanı sıra, pahalı ekipmanlara ihtiyaç duyulmaksızın oldukça estetik restorasyonlar yapılması avantajını sağlamışlardır. Metal alt yapılara seramik materyallerin bağlanması maksimum dayanıklılık sağlamıştır, bu alt yapı sayesinde iç yarık ve çatlak yayılımı en aza indirilmiş olmaktadır.

3. Kristallerin cam faz içinde dağılması (çekirdek yapıyı güçlendirme); yüksek dayanıklıı̆ga ve elastisiteye sahip seramik kristalleri, dental seramiklerin camsı fazı içine dağıldığında, oluşan cam-kristal birleşimi dayanıklılıkta ve elastikiyette artışa neden olmaktadır. Bu daha sert kitle, çatlak yayılımını engeller, böylece kırılganlık da azalır. ${ }^{22}$ Alüminayla güçlendirilmiş kor materyali, feldspatik porselenden iki kat daha fazla eğilme dayanıklıığına sahiptir. Bu dayanıklııktaki artış kristal fazın konsantrasyonu ile ilgilidir. ${ }^{18,19,24}$

4. Camların kristalizasyonu; camın kontrollü kristalizasyonu dental seramiklerin güçlendirilmesinde diğer bir metottur. ${ }^{18,25}$ Isı uygulaması sırasında, iç kristallerin büyümesi ve nükleasyon ile kontrollü kristalizasyon meydana gelir. Bu kontrollü kristalizasyon cam boyunca eşit olarak dağılan küçük kristallerin oluşumuna neden olur. Kristallerin sayısı ve büyüklüğü, ISI uygulamasının süresi ve ISI derecesi ile ayarlanır. ${ }^{26}$

5. İyon değişimi ile kimyasal sertleştirme; bu teknik yüzeydeki çatlakların ilerlemesini engellemek amacı ile seramik yüzeyinde düşük ısıda kompresif 
bir tabaka oluşturmayı amaçlar. Cam matriks içindeki bazı iyonlar daha büyük iyonlarla değiştirilerek yüzeyde kompresif bir tabaka elde edilir. Seramik cam, geçiş ısısının altında erimiş tuz banyosuna daldırılır. Bu ısılarda cam rijid bir yapıdadır. İyonik hareketlerin oluşabilmesi için yeterli olan bu ısıda sadece alkali iyonlar yer değiştirebilecek kadar hareketlidir. Seramikdeki $\mathrm{Na}+$ iyonları $\mathrm{KNO}_{3}$ banyosundaki $\mathrm{K}+$ iyonları ile yer değiştirir. Sodyumdan daha geniş bir hacim kaplayan potasyum iyonları, silikat ağını sıkıştırarak kompresyonu gerçekleştirir. ${ }^{20} \mathrm{Bu}$ sıkıştırılmış alan çekme kuvvetlerinin mikro çatlaklar üzerindeki etkisini azaltmaktadır. Çatlaklar ilerlemeden önce baskı gerilimlerini aşması gerektiği için, şartlandırılmış bu yüzeyler, seramik kırılmadan önce oldukça büyük yüklenmeleri kaldırabilmektedir. ${ }^{27}$

6. Mine ve dentine bağlanma; seramiklerin mineye bağlanma dayanımları oldukça iyidir. Dentine bağlanma dayanımı yapılan yeni çalışmalarla gün geçtikçe arttırılmakta ve mineyle olan bağlantısına rakip olmaktadır. Mineye bağlanma ile zayıf seramik restorasyonlar önemli derecede güçlendirilir. Preparasyon sırasında diş yapısından madde kaldırmaya olan ihtiyaç minimumdur. Eğer seramik restorasyonlar diş yapısına yeterince bağlanabiliyorsa, yapılan restorasyonun dayanıklılığı orijinal dişin dayanıkılı̆̆ına yakın olacaktır. ${ }^{18}$

7. Yüzey işlemleri; polisaj, glaze, otoglaze, basınç altında soğutma işlemlerini kapsamaktadır. Tesviye sonrası seramik yüzeylere uygulanabilecek polisaj işleminin, seramik yüzeyini daha düzgünleştirdiğine, düzgünleştirilmiş yüzeylerde gerilim birikimlerinin daha düşük düzeyde olacağına ve böyle düzgün yüzeylerde yapılan glaze işleminin daha başarılı olabileceği savunulmaktadır. ${ }^{28}$

Simantasyondan önce son yüzey işlemi olarak önerilen glaze porselene düzgün ve parlak bir yüzey kazandırırken, yüzey mikro çatlaklarının ve yüzey pörözitelerinin boyutlarının küçülmesini sağlamaktadır. ${ }^{29}$

Seramiğin fırınlanması sırasında tam olarak sinterizasyonun oluşması ve pöröz yapıların doldurulması sonucu seramiğin yüzeyinde parlak ve kaygan bir katman oluşur ki buna "natürel glaze" adı verilir. Bu sayede seramik, kütlesel bütünlüğe erişir ve dayanıklıı̆ı artar. $^{28}$ Natural glaze işlemi; seramiğin fırınlandıktan sonra fırından çıkarıır çıkarılmaz basınçlı hava altında soğutulması esasına dayanır. Yapılan araştırmalarda hava basıncı miktarı ortalama $0.34 \mathrm{MPa}$ olarak belirlenmiştir. Bu uygulama porselen yüzeyinde oluşan baskı gerilimlerini ve mikroçatlakların ilerlemesini engelleyerek, porselenin eğilme dayanıklıı̆ını arttırmaktadır. ${ }^{29}$

8. Sertleştirme dönüşümü; son dönemlerde tam seramik restorasyonların yapımında kullanılan zirkonyum oksit ısıya bağlı olarak farklı kristal yapılarda bulunmaktadır. Bu kristal fazlar kübik, tetragonal ve monoklinik fazlardır. Materyalin mekanik özellikleri birinci olarak tetragonal fazmonoklinik faz dönüşümüne bağlıdır. Bu dönüşüme dıştan uygulanan stresler neden olmakta ve kristallerin hacminde $\% 3$ ila \% 5 oranında bir artış olmaktadır. $\mathrm{Bu}$ sayede, çatlakların ilerlemesine karşı koyacak iç stresler gelişmekte ve çatlak yayılımına materyalin direncinin artmasında rol oynamaktadır. Bundan dolayl; yttria kısmen stabilize edilmiş tetragonal zirkonya polikristalin seramikler ve diğer zirkonyayla güçlendirilmiş seramikler, konvansiyonel seramiklere kıyasla oldukça yüksek kırılma dayanıklıı̆ı gösterirler. ${ }^{30}$

Tam Seramik Sistemlerin Endikasyonları ve Kullanım Alanları

Dişhekimliğinde yapılan tedavi seçeneklerinin hepsinde estetik, gerek hastanın gerekse hekimin en çok üzerinde durduğu konulardan birisidir. Dişin doğal rengi, ışığın direkt olarak diş yüzeyinden ve içeri giren ışığın dentin ve mine tabakasından geçerek yansıması seklinde oluşur. Renk yüzey yapısından, restorasyonu çevreleyen dişeti dokusundan ve ortamın ışığından etkilenir.

Yapılan restorasyonlar renk derinliği, ışık geçirgenliği ve doğal dişte bulunan anatomik yapısal özellikleri taklit edebilmelidir. Doğal diş, ışığın iletilmesine izin verirken, metal destekli seramik kuron sadece ışı̆̆ın yansımasına izin verir. Tam seramik restorasyonlar ışık iletimine izin verdiklerinden, komşu dişlerle uyumlu bir estetiğe ulaşılabilinmesinde başarıyla kullanılabilen materyallerdir. ${ }^{31,32}$

\section{Endikasyonları ve Kullanım Alanları}

1. Çürük, aşınma, kırılma ve renklenme görülen dişlerde,

2. Estetiğin öncelikli olduğu ve kapanışta yeterli mesafenin bulunduğu vakalarda,

3.Normal diş kavsi dışında yer almış dişlerde, anatomik yapıyı sağlayarak estetik ve çapraşıklığı

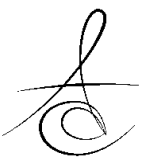


düzenlemek amacıyla,

4. Diş yapısının ve periodontal sağı̆̆ın mutlak korunması gerektiği durumlarda, tam seramik restorasyonlar kullanılabilmektedir. ${ }^{34}$

\section{Tam \\ Seramik}

\section{Kontrendikasyonları}

1. Diş kesimi sonrası kapanış mesafesinin $1^{\prime} \mathrm{mm}$ den az olduğu durumlarda,

2. Kesim sonrası tutuculuğun en alt seviyede olacağı kuron boyunun çok kısa olduğu dişlerde ve periodontal desteği yetersiz olan dişlerde,

3. Bruksizm veya düzeltilemeyecek düzeyde maloklüzyonu olan vakalarda,

4. Daha önce basamaksız kesimin yapılmış olduğu dişlerde,

5. Örtülü kapanış ve ileri itimin artmış olduğu vakalarda,

6. Kuvvetli ve aktif kas sistemine sahip olan pipo kullanımı veya bazı meslek alışkanlıklarına sahip olan bireylerde, tam seramik kuronların uygulanması tercih edilmemelidir. ${ }^{34}$

Tam Seramik Sabit Restorasyonların

\section{Avantajları}

1. Metal-seramik restorasyonlarda görülen, alaşıma bağlı dişetindeki gri renklenme, korozyon, toksik ve alerjik etkiler, translusensi eksikliği tam seramik restorasyonlarda görülmemektedir.

2. Seramiğin iç yüzeyindeki opak tabakasından doğan, doğal olmayan yansımalar ve metal bantlı bir görünüme sahip olmadıklarından mükemmel bir estetiğe sahiptir.

3. X-ışınlarına karşı geçirgen oldukları için, mevcut dolgu ve kuron altındaki dişin kök kanalı rahatıkla görülebilir.

4. Seramik restorasyon ve alt yapısı kusursuz bir birleşme yaptığı için, metalle olan birleşmedeki gibi kabarcık, çatlak, ayrılma görülmez.

5. Metal destekli seramik restorasyonlardaki gibi gelen ışığın yansıması ve saçılması gibi optik olaylar olmadığından, gelen ışık büyük oranda kuron içinden geçebilir, böylece doğal dişe yakın görünüm sağlar. . $^{34,35}$

\section{Tam Seramik Sabit Restorasyonların}

\section{Dezavantajları}

1. Basamaklı kesim gerektiren seramik sisteminde üst çene arka bölge uygulaması zordur.

2. Diş kesimi metal destekli seramik kuronlara göre daha çok ayrıntı gerektirir.
3. Laboratuar çalışmaları daha çok dikkat ve titiz bir çalışma gerektirir.

4. Maliyeti yüksektir.

5. Ek laboratuvar ekipmanı gerektirir.

6. Kırılgandırlar. ${ }^{29,34}$

\section{SONUÇ}

Günümüzde kullanılan tam seramik restorasyonlar doğal dişe en yakın renk ve ışık geçirgenliğine sahip olmaları nedeniyle en fazla tercih edilen restorasyon tipleridir. Seramik materyalinin fiziksel ve mekaniksel özelliklerinin geliştirilmesi klinikte kullanımlarını da arttırmıştır. Ancak kırııganlık dezavantajının hala tam olarak giderilememiş olması, tam seramik sistemler ile ilgili detaylı araştırmalar yapılması gereğini göstermektedir.

\section{KAYNAKLAR}

1. Efeoğlu A. Diş Hekimliği Tarihi. Alemdar Ofset; İstanbul:1992. p.23-87.

2. Alkumru $H$, Hullah $W R$, Marquis PM, Wilson $H J$. Factors affecting the fit of porcelain jacket crowns. British Den J 1988;164:39-43.

3. Boening KW, Walter MH, Reppel PD. Non-cast titanium restorations in fixed prosthodontics. J. Oral Rehabil 1992;19: 281-7.

4. Mehulić M, Mehulić K, Kos P, Komar D, Katunarić $M$. Expression of contact allergy in undergoing prosthodontic therapy patients with oral diseases. Minerva Stomatol. 2005 May;54:303-9

5. Rosentiel SF, Land MF, Fujimoto J. Contemporary fixed prosthodontics. The C. V. Mosby Company, 643-72, 2001.

6. Schwickerath H. Ceramic-metal crowns, Quintessenz Zahntech. 988;14: 1147- 51.

7. Akın E. Diş Hekimliğinde Porselen. III. Baskı. G.Ü Basım Evi ve Film Merkezi; İstanbul: 1990.p.7-10, 232-4.

8. Heather J.C., Wook-Jin S. Igor J.P. Current ceramic materials and systems with clinical recommendations: a systematic review. J Prosthetic Dent. 2007;98:389-404.

9. McLean JW. The Science and art of dental ceramics. Vol.I. Quintessence Publishing Co; Tokyo: 1980.p.30-57.

10. Yavuzyılmaz H. Metal Destekli Estetik (Veneer-

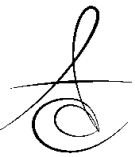


kaplama) Kuronlar. Gazi Üniversitesi İletişim Fakültesi Basım Evi; Ankara: 1996.p.13-25.

11. Sadowsky SJ. An overview of treatment considerations for esthetic restorations: A review of the literature. J Prosthet Dent 2006;96:433-42.

12. James D.W., Glen H.J., David J.B. Marginal adaptation of castable ceramic crowns.J Prosthetic Dent. 1991;66:747-53.

13. Reich S, Schierz O. Chair-side generated posterior lithium disilicate crowns after 4 years. Clin Oral Investig 2012 (Epub ahead of print)

14. Suarez MJ, Lozano JF, Paz Salido M, Martinez F. Three-year clinical evaluation of In-Ceram Zirconia posterior FPDs. Int. J Prosthodont 2004;17:35-8.

15. Zhao K, Pan Y, Guess PC, Zhang XP, Swain MV Influence of veneer application on fracture behavior of lithium-disilicate-based ceramic crowns. Dent Mater 2012;28:653-60.

16. Heintze S.D, Rousson V. Fracture rates of IPS Empress all-ceramic crowns-a systematic review. Int J Prosthodont 2010;23:129-33.

17. Pascal M., Kung-Rock K., Urs C.B., James S.H., William H.D. Crack Propensity of porcelain laminate veneers: a simulated operatory evaluation. J Prosthetic Dent. 1999;81:327-34

18. Craig RG. Restorative dental materials, 10th ed, Mosby Yearbook; St Louis: 1997.p.113-147.

19. O'Brien WJ. Dental Materials and their selection. Quintessence Publishing Co.Inc; Chicago: 1997.p. 91-125.

20. Zaimoglu A, Can G. Sabit protezler, A. Ü. Diş Hek. Fak. Yayınları; Ankara: 2004.p. 25-77.

21. Esquivel-Upshaw J, Rose W, Oliveira E, Yang M, Clark AE, Anusavice K. Randomized. Controlled Clinical Trial of Bilayer Ceramic and Metal-Ceramic Crown Performance. J Prosthodont. 2012 Sep 14. doi: 10.1111/j.1532-849X.2012.00913.

22. Crispin B. J. Contemporary Esthetic Dentistry: Practice Fundamentals. Quintessence Pub Co, Inc; Tokyo:1994.p. 71-123.

23. Lofstrom L. H, Barakat MM. Scanning electron microscopic evaluation of clinically cemented cast gold restorations. J Prosthet Dent 1989;61:664-9.

24. Ricardo S., Igor S.M., Paulo F.C., Adeliani A.C., Antonio C.H. Porcelain monolayers and porcelain/alumina bilayers reinforced by $\mathrm{Al}_{2} \mathrm{O}_{3} / \mathrm{GdAlO}_{3}$. J Mechanical Behav. of Biomedical M. 2012;5:110-5.
25. Kern M, Thompson VP. Sandblasting and silica coating of a glass-infiltrated alumina ceramic, volume loss, morphology, and changes in the surface composition. J Prosthet Dent 1994;71: 453-61.

26. Van Noort R. Introduction to Dental Materials. Chapter 3,4: Dental Ceramics, 2ND ED., Mosby Yearbook; St Louis:2002.p.29-63.

27. Zan T. Çeşitli yüzey şartlandırma işlemlerinin konvansiyonel dental porselenlerin eğilme dayanıkıı̆̆ı üzerine etkisi. G Ü Sağlık Bilimleri Enstitüsü, Doktora Tezi; Ankara:1999. P.15-19.

28. Aksoy G. Dental Seramiklerde Glazür Katmanının Önemi, E. Ü. Diş Hek FakDerg 2003;24:103-11.

29. Yavuzyılmaz H, Turhan B, Bavbek B, Kurt E. Tam porselen sistemleri II, G. Ü. Diş Hek Fak Derg 2005;22:49-60.

30. Luthardt RG, Holzhüter M, Sandkuhl O, Herold V, Schnapp JD, Kuhlisch E, Walter M. Reliability and properties of ground Y-TZP-Zirconia ceramics, ] Dent Res 2002;81:487-91.

31. Lehner CR, Scharer P. All ceramic crowns.Current Opinion in Dentistry 1992;2:42-45.

32. Wall GJ, Cipra DL. Alternative crown systems. Dental Clinics of North America 1992; 36:765-79.

33. Giordano RA. Dental ceramic restorative systems. Compendium 1996;17:779-94.

34. Toksavul S, Artunç C, Ulusoy M, Toman M. Tüm Seramik Kronlar. Meta Basım Bornova; İzmir: 2002. p.3-8.

35. Boening, KW, Wolf $B H$, Schmidt $A E$, Kastner $K$, Walter MH.Clinical fit of procera all-ceram crowns, J Prosthet Dent 2000;84:419-24.

\author{
Yazışma Adresi \\ Dr. Cumhur KORKMAZ \\ Balıkesir Asker Hastanesi \\ Diş Servisi - BALIKESİR \\ Telf: 2662396000 \\ e-mail: cmhkorkmaz@hotmail.com
}

